\title{
Unicornuate uterus and pregnancy outcome: a case report
}

\author{
Vineet Mishra*, Priyankur Roy, Bhumika Vyas, Rohina Aggarwal, \\ Shaheen Hokabaj, Raveendra Gondhali
}

\begin{abstract}
Department of Obstetrics and Gynaecology, Institute Of Kidney Disease and Research Centre, Ahmedabad, Gujarat,
\end{abstract} India

Received: 23 September 2016

Accepted: 20 October 2016

*Correspondence:

Dr. Vineet Mishra,

E-mail: vineet.mishra.ikdrc@gmail.com

Copyright: (c) the author(s), publisher and licensee Medip Academy. This is an open-access article distributed under the terms of the Creative Commons Attribution Non-Commercial License, which permits unrestricted non-commercial use, distribution, and reproduction in any medium, provided the original work is properly cited.

\begin{abstract}
Mullerian duct anomalies (MDAs) are congenital defects of the female genital tract that arise from abnormal embryological development of the Mullerian ducts. Unicornuate uterus with or without rudimentary horn is developmental anomaly which occurs due to abnormal or failed development of one of the paired mullerian duct or fusion of the ducts. Women with unicornuate uterus have increased incidence of obstetric complications like spontaneous abortions, preterm delivery and intrauterine foetal demise and gynaecological complications like infertility, endometriosis and dysmenorrhoea. A 25 years old, primigravida was admitted at 38 weeks 3 days gestational age with complaints of leaking per vaginum. She was induced with PGE2 gel under antibiotic coverage to prevent chorioamnionitis. She underwent emergency caesarean section for failure to progress and intra-operatively she was incidentally found to have unicornuate uterus with contralateral fallopian tube directly getting attached to the ovary. The baby cried immediately after birth, though it was growth retarded (IUGR). If pregnancy with unicornuate uterus is managed well, it can result in favourable obstetric outcome.
\end{abstract}

Keywords: Caesarean section, IUGR unicornuate uterus

\section{INTRODUCTION}

Congenital uterine anomalies result from an abnormal formation, fusion or reabsorption of Mullerian ducts during fetal life. The incidences of these anomalies are $0.5 \%$ to $5 \%$. MDA leads to complications like infertility $(2-8 \%)$ and is also a major cause of miscarriages (5$30 \%) .{ }^{1}$ It is also associated with an increased risk of preterm birth, preterm premature rupture of membranes, breech presentation, caesarean section, placenta previa, placental abruption and intrauterine growth retardation (IUGR). ${ }^{2}$

Unicornuate uterus is present in $0.1 \%$ of the population. The reproductive performance of women with unicornuate uterus is poor, with a live birth rate of only $29.2 \%$, prematurity rate of $44 \%$, an ectopic pregnancy rate of $4 \%$ and the fetal wastage rates are approximately
$24.3 \%$ in the first trimester, $9.7 \%$ in the second trimester and $10.5 \%$ can have intrauterine fetal demise. ${ }^{3,4}$

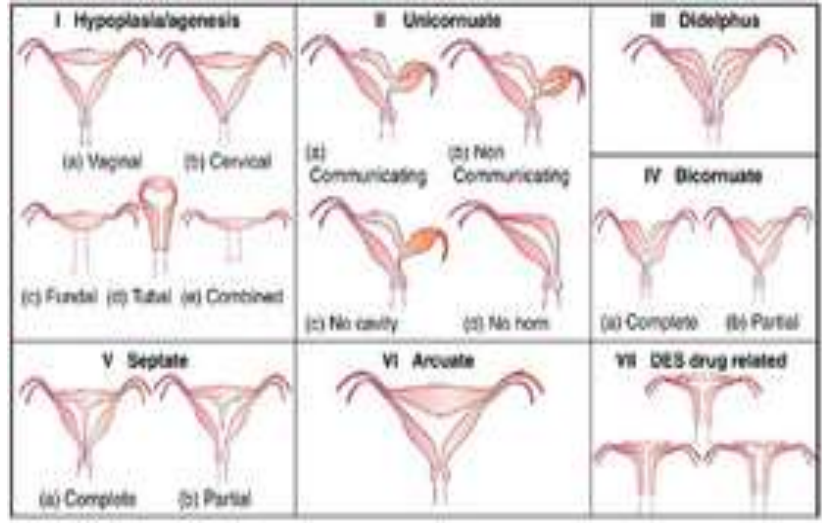

Figure 1: Unicornuate uterus with no rudimentary horn. 
It has been suggested that first trimester abortion, intrauterine growth restriction and stillbirths, are a result of abnormal uterine blood flow and second trimester abortions and preterm deliveries are thought to be due to decreased muscle mass in the unicornuate uterus as well as cervical incompetence.

A unicornuate uterus is a type II classification with unilateral hypoplasia or agenesis that can be further subclassified into communicating, no cavity and no horn. ${ }^{5}$

We present a rare case report of a successful pregnancy in a woman with unicornuate uterus and no rudimentary horn.

\section{CASE REPORT}

A 25 years old, primigravida, underwent her ANC elsewhere presented to the OPD, Institute of Kidney Diseases \& Research Centre, Ahmedabad, at 38 weeks 3 days gestational age with complaints of leaking per vaginum since 4 hours. She did not have any prior ultrasonography reports with her.

On admission, she was afebrile. She was fairly built and nourished, and her vital signs were within normal limits. Examination of her abdomen was suggestive of term pregnancy, estimated fetal weight of $2.5-2.6 \mathrm{kgs}$ with prominent fetal parts. Gross pooling of clear fluid was found on speculum examination. Admission NST was performed and it was normal. Her routine blood and urine investigations were within normal limits.

She was induced with PGE2 gel and parenteral antibiotic coverage was also started to prevent chorioamnionitis. Her post-induction fetal heart tracing was category one, showing a baseline fetal heart rate of $150 \mathrm{bpm}$, moderate variability, with accelerations and no decelerations. She started developing labour pains and per-vaginal examination performed 6 hours later showed $4 \mathrm{~cm}$ dilatation. Oxytocin augmentation was initiated and she developed 3 contractions lasting for 35 seconds in a period of 10 minutes. Repeat per-vaginal examination 4 hours later revealed the same dilatation.

She was taken up for emergency caesarean section for failure to progress and intra-operatively she was incidentally found to have unicornuate uterus with no rudimentary horn (Figure 1) and contralateral fallopian tube directly getting attached to the ovary (Figure 2). The baby cried immediately after birth, though it was growth retarded (birth weight $-2.3 \mathrm{kgs}$ ). She did not have any post-partum haemorrhage and the uterus was closed in one layer. Abdomen was closed in layers. She had an uneventful post-op recovery and was discharged from the hospital on post-operative day 3 .

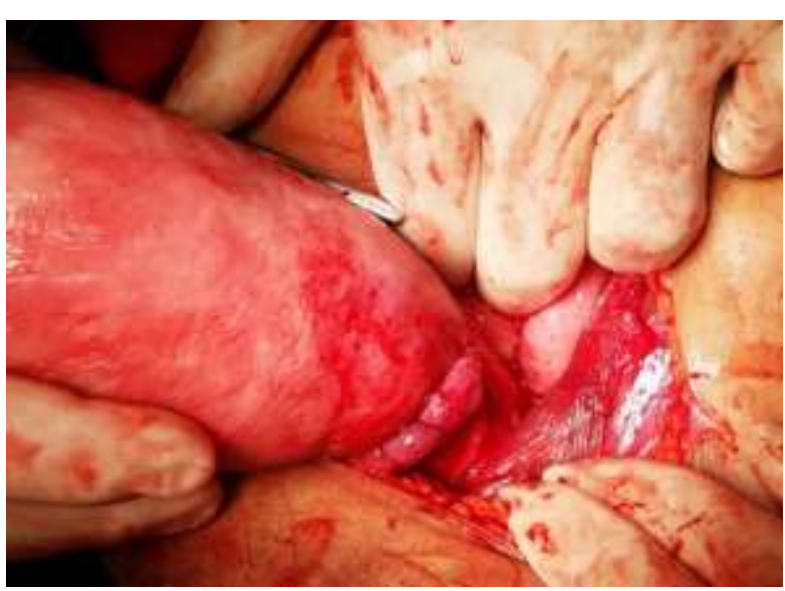

Figure 2: Intra-op picture of unicornuate uterus with no rudimentary horn.

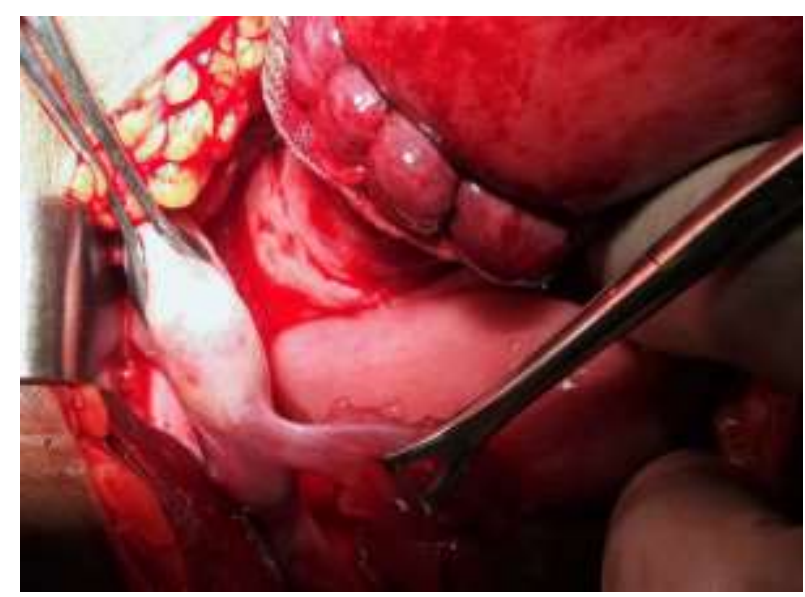

Figure 3: Intra-op picture of contralateral fallopian tube directly getting attached to the ovary.

\section{DISCUSSION}

Patients who have a unicornuate uterus with or without rudimentary horn have an increased incidence of gynaecologic problems in addition to the above mentioned obstetric problems and tend to present, at menarche or later in their life, with symptoms such as dysmenorrhea and chronic pelvic pain. ${ }^{6}$

Wang et al. presented 26 cases of unicornuate uterus with rudimentary horn, four of which $(15 \%)$ had become pregnant, and one of which (4\%) had been presented with ipsilateral oviduct ectopic pregnancy. ${ }^{7}$ Heinonen mentioned 93 pregnancies and only two of them had term delivery. ${ }^{8}$ Fox et al, suggested that the risk of adverse pregnancy outcomes was increased in patients with uterine unicornis and the rate of preterm birth was almost $50 \%$. ${ }^{9}$ Even though the obstetrical outcome is usually poor, there are some case reports that present with successful pregnancies. Gerris et al, reported successful triplet pregnancy in a patient with a unicornuate uterus with a cavitary communicating rudimentary horn. ${ }^{10}$ 
Caserta et al. reported a 39 weeks pregnancy with successful outcome after caesarean section. ${ }^{11}$

A unicornuate uterus with rudimentary horn is often associated with ectopic pregnancies and with rupture of the rudimentary horn and, although it is unclear whether or not to remove the rudimentary horn before conception or early in pregnancy, its resection improves obstetric outcomes. According to the current guidelines of the American Congress of Obstetricians and Gynecologists (ACOG) for the management of IUGR, it is reasonable to consider serial growth ultrasound examinations in pregnancies at risk of IUGR as in the case of a unicornuate uterus pregnancy. ${ }^{12}$

\section{CONCLUSION}

As a contribution to the literature, we herewith have a case report of a patient with unicornuate uterus with no rudimentary horn and contralateral fallopian tube directly attaching to the ovary. The significance of the attachment of the fallopian tube to the ovary is not known though. Thus, a very important message both for doctors and anxious patients with unicornuate uterus, as this anomaly has already been known to provoke obstetric and gynaecologic problems is that with good monitoring and timely interventions, the materno-fetal outcome is not always adverse.

Funding: No funding sources Conflict of interest: None declared

Ethical approval: Not required

\section{REFERENCES}

1. Chan YY, Jayaprakasan K, Tan A, Thornton JG, Coomarasamy A, Raine-Fenning NJ. Reproductive outcomes in women with congenital uterine anomalies: a systematic review. Ultrasound Obstet Gynecol. 2011;38:371-82.

2. Hua M, Odibo AO, Longman RE, Macones GA, Roehl KA, Cahill AG. Congenital uterine anomalies and adverse pregnancy outcomes. Am J Obstet Gynecol. 2011;205(6):558.

3. Akar ME, Bayar D, Yildiz S, Ozel M, Yilmaz Z. Reproductive outcome of women with unicornuate uterus. Aust N Z Obstet Gynaecol. 2005;45(2):14850 .

4. Reichman D, Laufer MR, Robinson BK. Pregnancy outcomes in unicornuate uteri: A review. Fertil Steril. 2009;91(5):1886-94.

5. Grimbizis GF, Campo R, Gordts S, Brucker S, Gergolet M, Tanos V, et al. On behalf of the Scientific Committee of the Congenital Uterine Malformations (CONUTA) common ESHRE/ESGE working group. Clinical approach for the classification of congenital uterine malformations. Gynecol Surg. 2012;9:119-29.

6. Khati NJ, Frazier AA, Brindle KA. The unicornuate uterus and its variants. Clinical presentation, imaging findings, and associated complications. J Ultrasound Med. 2012;31:319-31.

7. Wang SJ, Oli M, Jinag L, Wang JL, Wei LH. Clinical analysis of 225 women with congenital uterine malformation. Zhonghua Fu Chan Ke Za Zhi. 2008;43(7):493-6.

8. Heinonen PK. Unicornuate uterus and rudimentary horn. Fertil Steril. 1997;68(2):224-30.

9. Fox S, Ashley S, Erica M, Rachel S, Daniel H, Andrei R. Type of congenital uterine anomaly and adverse pregnancy outcomes. The Journal of Maternal-Fetal and Neonatal Medicine. 2014;9:94953.

10. Gerris J, Eulaers E, Joostens M, Jacquemyn Y, Loquet P, Verdonk P, et al. Successful triplet pregnancy in a patient with a unicornuate uterus with a cavitary communicating rudimentary horn. Hum Reprod. 1993;8(2):338-41.

11. Caserta D, Mallozzi M, Meldolesi C, Bianchi P, Moscarini M. Pregnancy in a unicornuate uterus: a case report. Journal of Medical Case Reports. 2014;8:130.

12. American Congress of Obstetrics and Gynecology Committee on Practice Bulletins- Obstetrics. ACOG practice bulletin: intrauterine growth restriction. Obstet Gynecol. 2000;95:1-12.

Cite this article as: Mishra V, Roy P, Vyas B, Aggarwal R, Hokabaj S, Gondhali R. Unicornuate uterus and pregnancy outcome: a case report. Int $\mathbf{J}$ Reprod Contracept Obstet Gynecol 2016;5:4522-4. 